\title{
An Exploratory Study on American- Born Imams: Negotiating Pastoral Responsibilities and Expectations
}

\author{
Anas Askar \\ Howard University, USA
}

DOI: https://doi.org/10.18778/1733-8077.17.3.05

Keywords:

Islam; Imam;

Muslim; Mosque;

American;

Symbolic

Interactionism

\begin{abstract}
Symbolic interactionism, applied in the context of Muslim clerics, suggests that society is constructed based on lived experiences and shared symbolic meanings where people see themselves and the social environment through the eyes of others. For this study, data collected from in-depth interviews were examined to investigate the viewpoints and occupational pathways of American born imams. Thus, this study explored the responsibilities assigned to imams and their communal objectives. Overall, this study found several challenges that imams experienced, professional and organizational. Utilizing symbolic interactionism, these issues were explicated, and the following overarching themes were generated: imams received inadequate training as religious leaders in their communities, relationships between the mosque board and an imam can directly reinforce or mitigate a challenging work environment, and it is most advantageous for American communities to hire American-born imams over foreign-born imams. The findings indicate that organizational support extended to imams from mosque boards leads to not only an amicable relationship but more productive community engagement.
\end{abstract}

Anas Askar recently graduated with a Ph.D. in Sociology \& Criminology from Howard University. His research interests include green criminology, environmental victimization, Muslim-Americans, and medical sociology. His publications include "Understanding Muslim Assimilation in America: An Exploratory Assessment of First \& Second-Generation Muslims Using Segmented Assimilation Theory" (Journal of Muslim Minority Affairs [with Amin Asfari]).

email address: anas.askar@bison.howard.edu

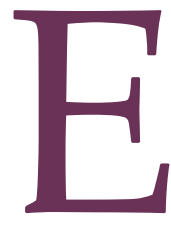
tymologically, the Arabic word "imam" may mean to guide, direct, or a prayer leader (Ansary 2009; Abuelezz 2011). Imam implies somebody, subsequently, who has some administrative or leadership capacity whether or not the individual is acceptable or malevolent (Abuelezz 2011). Notwithstanding, this definition is lacking when applied to imams dwelling in America as imams are required to lead prayer, fill in as instructors, and advocate for social justice (Haddad 1999). The jobs of imams are like Chris- 
tian pastorate and Jewish rabbinate individuals (Ali, Milstein, and Marzuk 2005).

In addition to religious knowledge, imams are expected to be culturally mindful of different Muslim backgrounds and have the necessary communication skills to relate with diverse ethnicities. Acknowledging the influence of spiritual leaders, Weber (1993:76) observed, "the pastor will be consulted in all the situations of life by both private individuals and the functionaries of groups. Among those whose pastoral care has influenced the everyday life of the laity and the behavior of political officials in an enduring and often decisive manner include Muslim imams." Similar was stated by Ibn Khaldun (1967), who documented that imams were revered due to their religious status and were approached with different issues due to their scholarly knowledge and praise-worthy characteristics.

This paper offers insight into imams' struggles, despite their cultural competence, and their complex challenges of identifying their place internally within religious institutions and outside their institutions. As a result of their experiences, many imams maintain that foreign-born imams may struggle to culturally adapt to the American context, considering the vast roles the position demands. The analysis begins with a historical background of Muslims' arrival to the United States, the establishment of Islamic institutions, and the routine tasks that imams perform. Utilizing a symbolic interactionist theoretical approach, imams symbolize leadership and serve as liaisons by representing their communities' interests, more accurately, American communities. An analysis of American-born imams' experiences reveals a lack of structural support from mosques and the extensive, rare, yet sought-after requirements of satisfying the imam profession.

\section{Background}

Understanding the struggles associated with building Islamic institutions (e.g., mosques) and establishing the role of imams within their respective communities requires a brief overview of Muslims' history in America. Accounts trace Muslim migration to America before Columbus. However, this viewpoint is considered controversial among some historians (Nyang 1999; Van Sertima 2003; Abu-Bader, Tirmazi, and Ross-Sheriff 2011). Research indicates that the coerced enslavement of Black and Brown bodies that came to America, via the Atlantic slave trade, an estimated $30 \%$ of Africans were Muslims (Al-Islam 2006). Also, Muslims came to the United States through immigration beginning in the year 1875 to 1912, where the earliest immigrants were of Syrian and Lebanese descent (Nyang 1999; Al-Islam 2006). In terms of mosque-related rituals, the first documented Friday prayer took place in Ross, North Dakota, in the early $20^{\text {th }}$ century (Nyang 1999). In addition, Detroit (MI) and Cedar Rapids (IA) were the earliest cities to build mosques in America (Nyang 1999). In 1965 and thereafter, Muslim immigrants were keen on building religious institutions that sought to preserve their identities and simultaneously encouraged civil engagement (Zaman 2008).

\section{Masjid (Mosque) Role and Structure}

The term masjid, or mosque, is described as a place of worship that is derived from the root word $s a$ jada, which means to prostrate (Omar 2005). The most original of studies that endeavored to reveal insight into mosques in America as organizations were by Haddad and Lummis (1987). The researchers were interested in how mosques served as institutions that advanced the integration process of 
Muslims in American life (Haddad and Lummis 1987). In the American context, with Muslims as minorities (1\% [Lipka 2017]), mosques may assume the role of acculturation into American culture where such a message can be disseminated (Cooley 1927). Furthermore, the underlying messages propagated within mosques are the following: religious identification, beliefs, and the practice of religious rituals (Gattino et al. 2016).

Relating to the administrative and managerial aspects of mosques, Nyang (1999) identified four different Muslim leadership models in America. First, a mosque in which there is a sole individual who oversees total control over mosque-related matters. A second model of leadership consists of a board of directors, who are usually the founding members of the mosque and assume the responsibility of recruiting and employing the imam. Third is a mosque that is affiliated with a central organization that usually hires a foreign-born imam who reports to and is supervised by the main organization. The fourth model of leadership is a hybrid one, where a board of director committee members is elected and then tasked to employ an imam while also serving as an independent institution from larger organizations. A later examination of mosque administration models omits Nyang's third model of institutions affiliated with larger umbrella organizations. This may be attributed to the expansion of mosque construction projects nationwide, which sought independence in the form of self-governance while also placing elected members on mosque board committees.

Furthermore, Bagby (2012) highlighted three mosque governance models where $47 \%$ of mosques are dually managed by a board and an imam. In this model, the board is responsible for administrative aspects of a mosque, and the imam directs the spiritual and instructional community needs. In the second model identified by Bagby (2012), the imam is the lone leader without the oversight of a committee board ( $31 \%$ of American mosques). As for $22 \%$ of mosques in America, the third model is where the committee mosque board dictates and governs the majority of mosque-related matters, while the imam plays a symbolic and small role. Noteworthy to mention, a clergy class is nonexistent within Islam, and the varying mosque models are meant to provide organizational structure, according to Weber (Djedi 2011).

\section{Imams}

An imam is defined as a leader, prayer and spiritual leader, an example, teaching authority, and a standard (Wehr 1994; Omar 2005). It is pertinent to be aware that through interactions with the Prophet Muhammad, Muslims and non-Muslims both characterized him as an honest and trustworthy individual (Al-Ghazali 1999). With this background, further support for the utilization of a symbolic interactionist approach becomes apparent when evaluating imams who seek to embody the prophet's tradition.

In addition, the term imam varies and holds specific meanings depending on the Islamic theological sect, whether one is mainly Sunni (90\% of Muslims) or Shiite (10\% of Muslims) (Al-Krenawi 2016). In Sunni theology, there is no clergy class or anointment of a divinely inspired imam, whereas, in Shiite theology, the imam is restricted to specific individuals who are considered infallible, beginning with Ali (Ibn Khaldun 1967; Al-Krenawi 2016). According to Shiites, the legitimacy of an imam lies mainly in the hereditary succession from the lineage of Ali and his wife Fatimah (Ibn Khaldun 1967). 
Historically, it has been the trend to hire immigrant imams since early accounts mentioned the Pittsburgh community hiring of an imam originally from Sudan (Nyang 1999). The practice of employing full-time imams from overseas continues till today, as only $15 \%$ of full-time paid imams were born in America (Bagby 2012). In fact, many mosques do not employ an imam on a part-time basis, and 19\% of mosques have no imam at all (Bagby 2012). As for full-time imams, they are tasked and overloaded with various responsibilities that lead to burnout as they take little to no vacation time. This is a theme across faiths, and some faith leaders have not had a vacation in 18 years, which undoubtedly takes a toll psychologically and emotionally (Vitello 2010a). Regarding burnout amongst Muslim faith leaders, Imam Shamsi Ali said, "We have all of these problems, but imams are reluctant to express it because it will seem like a sign of weakness. Also, mosques do not pay much and many of them work two jobs" (Vitello 2010a). By serving God and their congregants, imams epitomize what Cooley (1927) termed "social consciousness" (awareness of society) in tending to the needs of their community members, which could lead to exhaustion.

\section{Theoretical Framework}

In analyzing human interactions from a microlens, the European sociologist, Georg Simmel, influenced American sociologists George Mead, Charles Cooley, and Herbert Blumer into forming the symbolic interactionist perspective (Babbie 2004). Mead concluded that individuals develop the "generalized other" through the practice of empathy, thereby allowing one to consider life from other individuals' viewpoints (Babbie 2004). As a result of language and symbols, Mead suggested that individuals develop a common understanding and shared mean- ings (Babbie 2004). Similar to Mead, another sociologist who conceptually advanced the interactionist approach was Cooley, who developed the concept of the "looking glass self" where we see ourselves and the social world through the eyes of other people and often adopt those views (Aronson, Wilson, and Akert 2007).

However, it was Herbert Blumer who famously advocated for symbolic interactionist theory. Building upon Mead and Cooley, Blumer (1969) posited that the two main conceptual pillars of societal interactions were culture and social structure. Culture is viewed as the result of what people do, and social structure is the result of how relationships impact the way people act towards one another based on shared meanings (Blumer 1969). Charon (1979:36) wrote, "each individual depends on society for symbols, without other people, each individual would be without a symbolic life and all the things which symbols make possible." As Morgan (2010) outlined, ministers and imams symbolize sources of knowledge through their profession. Hence, imams are continuing to develop their identities based on societal relations and their socio-historical contexts (Scheuringer 2016).

\section{Methods}

For this study, in-depth and structured interviews were conducted with ten American-born imams across the nation. All interviews were completed between July and October of 2016 (see: Askar 2017; IRB approval through East Carolina University). Concerning the interview questions, the imams in this sample were requested to answer questions related to their career pathways, issues regarding the community's and their personal mental health, American political rhetoric, interfaith relationships, 
and stereotypes around the profession. To adequately address these discussion topics, questions were open-ended so that participants would voice their opinions using their language, resulting in rich and in-depth qualitative data (Stark and Roberts 1996; Denzin and Lincoln 2013). On its own, an in-depth exploratory study that yields rich data can diagnose social problems without the need for a deductive theoretical approach (Hammersley 2010).

Participant recruitment in the study was challenging, as contact with potential participants at a large Muslim conference yielded the participation of only one of the ten imams. The challenge in participant recruitment was attributed to three primary reasons: lack of contact between myself as the researcher and the participant imam, the focus on Muslims and minorities from politicians during the 2016 election, and issues with availability and scheduling conflicts. First, the lack of contact between myself as a researcher and an imam was a hurdle as the imams did not know me personally. In particular, many imams who were not local had no previous interaction with me, as I was unfamiliar to them due to distance. Second, the political rhetoric of the 2016 election, where there was talk of establishing registries for Muslim communities proposed by the Republican party, led to some reluctance and fear amongst potential participants. Lastly, for imams who agreed to participate, scheduling the interviews was a challenge due to their busy workloads. For some participants, flexibility in scheduling was critical, as participants rescheduled their interviews on multiple occasions.

To address some of the challenges related to my unfamiliarity with the participants, a list of potential participants was constructed from online databases and directories. Thereafter, I reached out to imams that were local by email and through in-person introductory greetings. Emails were sent out to twenty imams from the directory list requesting their participation in my study. From the first imam who agreed to participate (after a brief meeting in person), I resorted to snowball sampling (Babbie 2004), where the first imam then referred me to other imams who were willing to participate in my study. As a result, snowball sampling was an effective method towards contacting participants by building a rapport with the referrer that I could not have established without snowballing. In fact, my attempts to contact imams individually without an imam's referral yielded non-responses. In addition, although the interviews were recorded on my mobile phone, imams were reassured that their participation was confidential and that I would use pseudonyms. I also reminded the imams that their participation was voluntary, they had the absolute right to not answer a particular question, and they were free to leave the interview at any point. With this in mind, imams felt comfortable expressing their viewpoints while also referring my study to other participants.

In total, ten imams elected to participate in my study. As previously mentioned, building trust was vital, as my participants seemed more comfortable knowing one of their colleagues participated in my study more so than knowing I had IRB approval. To develop the initial trust of participants in me, I revealed my positionality as a researcher who shares the same faith as the respondents, which was comforting and reassuring towards building a relationship, albeit a temporary one since I had no prior association with the participants. Furthermore, my interest in the topic resulted from a palpable enthusiasm found amongst congregants upon hearing that an American-born imam was set to be hired in 
a community. This event was the impetus for my exploratory study. In terms of an operational definition, a potential respondent was any Muslim religious figure with Islamic knowledge regardless of ideology and who was born in America.

The interviews for this sample were conducted in-person, and for participants who were distant, the interviews took place through telephone. However, participants within driving distance were given the option to participate over the phone for convenience purposes. Three respondents participated in the interview face-to-face, and seven respondents were interviewed by phone. In terms of length, the shortest interview lasted 30 minutes, and the longest interview was an hour and 20 minutes. After completing the interviews, I transcribed the recordings from my phone, by which more than 130 pages of transcribed interview notes were generated. This sample's imams were racially and ethnically diverse, as the respondents were African American, Middle Eastern, Indo-Pakistani, and White. Also, some respondents were converts to Islam, while most were born into the Muslim faith.

\section{Findings}

\section{Inadequate Training for Imams}

A central theme that arose from the interviews was the inadequate preparation that this sample's respondents received. Although the respondents varied by religious educational attainment, they expressed the inadequacy of their training for the imam position. Specifically, by religious educational background, imams ranged from holding a certificate in Islamic studies to a doctorate in Islamic studies. In addition, this sample's imams were not lacking in experience, as the range in years serving as imams were between 1 year and up to 29 years (average was ten years of experience). Nevertheless, the wealth of experience and education attained did not lead this sample's respondents to feel qualified to serve. These feelings were expressed by both Imams William and Jacob, although they had experience teaching and serving on a part-time basis within mosques. Their feelings are confirmed and supported through Al-Krenawi's (2016) study, where the sentiment of inadequate training for the imam position was likewise prevalent among European imams and largely attributed to the expansive role an imam is required to fulfill.

When speaking about the need for training in pastoral care, Imams William and Tim cited the numerous expectations of imams (leads to mental health stressors among imams and clergy, see: Vitello 2010b; and Pooler 2011; Abbasi and Gassas 2016) that include family and marital issues, domestic abuse, substance abuse, counseling, media relations, public speaking engagements, and other matters. These expectations require training rarely found among imams as there is no formal process towards becoming an imam (Morgan 2010). According to the participants themselves and based on suggestions provided from the imams interviewed, possible explanations as to why there is insufficient institutional training of imams include: an unclear definition of the term imam, imams receive general non-contextual training and education rooted in the religious sciences and Muslim community's stereotypes associated with imams that devalue the position.

\section{Unclear Definition of the Term Imam}

The participants in this sample reasonably attributed inadequate training for their roles to the lack of a standardized definition of the term imam. 
This was obvious when the imams themselves differed as to what the term entailed. The participants found it challenging to explain the meaning of the term imam as Imam Stanley said, "Though I knew you were going to ask about that, I didn't really, unfortunately, give it the thought that it deserves. I don't think I really have a definition of the word imam." Relatedly, it was Goffman who proposed the idea that people construct and negotiate their identities to develop meanings of situations (Howard 2000). When it comes to imams, this negotiation of identity was evident as most imams in this sample agreed that an imam in America vastly differs from an imam in overseas countries where they are expected mainly (and sometimes solely) to lead prayer in a mosque (Abuelezz 2011). As such, Imam Malcolm provided a metaphoric answer in describing what an imam represents, "imam, the word itself has a root for the word mother. It comes from the same root word in Arabic, so it's like a mother." Considering the male-dominated field of imams, stating the term "mother" was an interesting and ironic parallel drawn by Imam Malcolm, requiring further exploration into gender biases. [Attempts were made to interview Muslim women chaplains and religious leaders, yet to no avail.] Perhaps, Imam Malcolm's utilization of the term "mother" as an imam aligns with other respondents' views, wherein the definition was fluid, according to Imams Jacob and William, who stated that an imam could be a scholar, or a community leader, and can carry other definitions that disregard specific roles.

By providing a diverse and varying set of definitions of the term imam, the respondents expressed that an absence of a distinct meaning of the term imam did not bode well for the position. On this, Imam Erick said, "when we all come to America and grow as a Muslim community, there's no coherent definition, then it's a position that is doomed to fail."

\section{General Education Lacking Cultural Context}

Another reason cited for the deficient preparation of an imam for the position is that overseas educational seminaries do not consider the American cultural context. Most imams in America study the Islamic sciences abroad, where the overwhelming majority $(94 \%)$ of imams obtained their degrees from overseas institutions (Bagby 2012). Compounding the issue, Islamic institutions and seminaries in America are still in their infancy (Burnett 2013), and contextual application issues arise from learning abroad (Abdul-Hakeem 2015). Although Imam Malcolm stated that there had been noteworthy progress and development of religious seminaries in America, another issue that Imam William brought forth is the shortage of competent imams in need across the nation. Accounting for the diversity in cultures was another critical challenge cited by Imams Tristan and William. Here, Imam William's quote suffices: "the research shows that the Muslim community is the most racially diverse faith community in America. And in an Islamic center, there was a study that found that more than 75 different nationalities represented the Islamic center."

Other contextual training issues cited by the imams included interfaith relations and addressing community members' mental health. Studies have cited the lack of mental health training and counseling as a significant flaw among educating imams (Al-Krenawi 2016). Regarding interfaith relations, Imam Tim believed that imams from foreign countries are not trained in interfaith work, which is an expectation of American imams. In my sample, all the respondents affirmed their involvement in interfaith dia- 
logues and outreach activities. Their involvement in interfaith work is comparable to the percentage $(79 \%)$ of mosques in America that participate in interfaith activities (Bagby 2012). In summary, studies have confirmed my respondents' attitudes towards establishing new comprehensive training programs in America, and domestic institutions are viewed as the best means towards training future imams (Abuelezz 2011).

\section{Imam Stereotypes and Devaluing of the Position}

The third reason cited as an explanatory factor for the inadequate training of imams is that imams are labeled and stereotyped by the Muslim community. In addition, congregants devalue the imam position and conclude that their salaries should be modest. The imams in my sample mentioned stereotypes they encountered internally from the Muslim community, which included being money-driven, culturally regressive, incompetent, and too spiritual for congregants to approach. Intriguingly, the imams in this sample were not immune from having stereotypes towards imams, which is captured in Imam Erick's statement, "my own experience growing up as a young teenager in America, I look at all the imams around me, and the first thing that comes to my mind is that these guys are from another planet." A stereotype held among Muslim congregants is that imams are financially motivated. However, Imam Calvin saw that his colleagues were underpaid, considering the immense expectations and desired requirements linked to the position. There appears to be a generational difference-in Imam Erick's experience, second-generation Muslims see the value of paying more for a qualified imam.

An additional stereotype that arose from this sample's imams was the idea among their congregants that they were unapproachable. As seen in Imam Michael's experience, he had to insist to community members that he was just a regular person. Also, Imam Tristan mentioned, "some people have some kind of superstition, and they might think you're a holy person or Allah [God] is going to answer your prayer or something like that." Commenting on the belief among congregants that imams view themselves above their constituents, Imam Stanley stated that congregants felt that an imam was keen on shaming them, and this false notion was damaging as it leads to communal distance and avoidance of interacting with imams.

Other stereotypes that imams tackled were incompetence and cultural backwardness. Imam Jacob was well aware of this stereotype and proceeded to defy the stereotype when he remarked: "So I try to sometimes go out of my way to kind of undo some of those stereotypes and let you know that, hey, I do have a science background, I do understand that the earth is round and it's not flat." Providing historical and background context, Imam William explained that overseas educational systems socialize their citizens to look down upon imams. Imam William said, "the number one highest-scoring students usually attend medical school, number two go to engineering, and, literally, the lowest-achieving students go to Arabic and Islamic studies." The ripple effect has extended to familial attitudes, where Imam Jacob said, "a lot of families who discourage people from or their kids from becoming imams... and so you should go back into a proper career."

The imams in this sample mentioned the lack of proper training for their profession. According to my data, three primary reasons arose in explaining the inadequate training of imams, which included: an unclear definition of the term imam, a general 
education in the religious sciences that did not account for the American context, and stereotypes attached to imams that have led to the undervaluing of the position from further development.

\section{Board Politics}

Usually, a mosque board comprises community members who originally founded and established the mosque from its inception. However, mosque boards present another challenge for imams as they negotiate fluctuating identities between the community and board members. In The Athaan in the Bull City, the author notes two of the most outstanding issues found within mosque boards, which include the complications associated with hiring a fulltime imam and intra-religious strife between Black Muslims and immigrant Muslims (Abdul-Hakeem 2015). In my study, disputes arose when the board disagreed with the imam's vision, which led to tension and a dissatisfying work environment between some of my participants and their respective boards.

The tension between the imam and the mosque's board led to some of my respondents' resignations from their positions. As such, three imams in my sample faulted the mosque board for their resignations and mentioned the disorganization found within their respective mosques. In addition, out of the ten imams interviewed, only one imam stated their non-involvement in board politics and said it dissuaded him from pursuing an imam position in the past. In the case of Imam Steven, after failed negotiations with the board, he said, "There was not a whole lot of conversation there. Then it was two weeks later that I called them into my office and I told them I was resigning. But, it was unfortunate because, in the end, everything was fine except for one person, but that one person had control." An- other respondent who spoke about the friction between himself and the board, Imam Erick, mentioned, "I do believe there is a mismatch between my vision of how I'd like to build a community and how the board members and the institution and direction that they wanted to go. So, a combination of a lack of professionalism, perhaps not the clearest path outlined by the community board."

Colleagues have encouraged their fellow imams to live bi-vocationally following the life of Imam W. D. Muhammad to have a second and separate source of revenue (Rashaad 2015). It appears that the resignation of imams in America is a pattern, as former imam Marc Manley (2015) resigned due to long-standing discrimination, a lack of mosque board support, and a dysfunctional community vision. Theoretically, symbolic interactionist theorists observed that functional organizations have "some leadership, some policymakers, some individuals who speak on behalf of the group, and some individuals who take the initiative in acting on behalf of the group" (Blumer 1969:199). According to my data, the underlying reasons that explain why imams encounter challenges with their respective committee boards are organizational, cultural, and visionary differences.

\section{Organizational Challenges}

According to the respondents, organizational and structural issues within mosque boards were manifested in their lack of experience needed to manage an operational staff of individuals. This is captured in the statement of Imam William, "I think even step one of the awareness of what we are expecting of imams is quite lacking among hiring teams and among masjid boards, the congregation, and all across America." Also, upon speaking about the 
peculiar hiring process, Imam Michael later found out that the board's search committee never saw his application, which he considered a sign of mismanagement and a poorly run administration. As it specifically relates to Imams Michael, Steven, and Erick, they resigned due to a dysfunctional mosque board. Imam Steven experienced four different mosque boards over two years, which indicates an unorganized organization.

The participants in my sample were surprised by the disorganization they experienced in working with mosque boards because of their professional backgrounds. Most of my sample (with one exception) did not actively pursue a career in serving as imams. My respondents' educational and professional backgrounds allowed them to experience a more organized structure than in the mosques they were employed. Since mosque boards exercised control over the institution, symbolic interactionist theorists mention how power has a significant impact in shaping meaning and the control of experiences (Rock 1979). These meanings and experiences left an indelible mark on Imam Erick as he observed, "I'm coming from the corporate world, there's a certain level of professionalism that you learn, and there's a way to navigate when it comes to hiring and negotiating these types of things, and I came to see that in the nonprofit Islamic world and the imam world it was very different." Imam Michael issued similar statements.

To improve and enhance board relations, several respondents offered suggestions in attempting to solve organizational issues. Imam Tim recommended a mosque model where the imam was the leader, and the board was set up to provide a type of checks and balances within the system. There has been a shift towards imams being leaders of their mosques. In $55 \%$ of mosques, the imam is considered the leader, a noteworthy percentage change from the year 2000 when $41 \%$ of mosques considered the imam as the leader (Bagby 2012). As a result of challenges with disorganized mosque boards, Imam Jacob advises future imams to exclusively accept positions if the mosque's system permits institutional reforms; if not, then one should work outside the mosque system.

\section{Cultural Challenges}

In addition to organizational issues, a second reason found in the transcripts as to why there were disputes between the board and the imams revolved around cultural matters. From the viewpoints of my sample, some respondents believed that mosque boards lacked diversity in thought and racial representation. Moreover, some imams described board members as inflexible, while others were power-driven. To prove their ability to control and lead mosque-related matters, board members viewed imams as individuals who would potentially infringe upon the authority of the committee board. Imam Erick commented that the board becomes uneasy when an imam is the community's visionary leader because the board views its role as the community's driver. In an example highlighting the extent to which the board impacts the freedom of imams to speak about certain issues, Imam Malcolm said, "A lot of the imams they may not feel comfortable, especially since you're in a paid position that sometimes you have to bite your tongue because this board that sits over you tells you to do this and do that."

The power struggle between the board and imam was also evident in what Imam Tim observed as a racial difference where in immigrant-led mosques, 
the imam has no authority, and the board yields the power. In comparison, in Black Muslim-led mosques, the imam is the sole community leader and the authority figure. Imam Tim's observations are supported in some studies where $69 \%$ of mosque boards hold the final decision (Bagby 2012). On the other hand, in Black Muslim-led mosques, the board has less influence than in immigrant-led mosques, where the last word is settled by a mosque board in only $25 \%$ of their mosques (Bagby 2012). Similarly, Imam Stanley attributed the struggle for power as a challenge rooted in the board's attained educational or socioeconomic status, which the board perceives would deem them as influential as the imam.

The influence of the board can repel imams from their occupations, as in the case of Imam Steven, who left the position due to the sway of a single board member. The decision made by Imam Steven and other imams to resign is a reflection of generational cultural differences. Annotating this perspective, Imam Calvin insisted that American-born imams would not tolerate being pushed around, but acknowledged that mosques needed to accommodate imams better. Consequently, the current relationship with mosque boards is unhealthy and unsustainable.

\section{Differences in Vision}

A combination of organizational and cultural differences between mosque boards and this sample's imams naturally lends to differences in vision. When a difference in vision occurs, a need for compromise arises, and sometimes, the board may need to approve the overall direction and vision of an imam. Nevertheless, Imam Tristan cited continued differences, and two respondents recalled their inability to continue pursuing higher education (as resident scholars) as legitimate and valid concerns leading to their resignations. The committee boards declined to support the educational attainment of the imams, as Imam Steven recalled, "I need time to study, even if it's just a handful of hours a week. And they didn't see the need for that, so, for me, that was kind of like the last straw...the work was going to destroy me; that's not going to be healthy."

In addition, clashes in vision between the board and imams centered on financial and hiring practices. In most mosques (61\%) in America with a full-time paid imam, the imam is often the only individual who is financially compensated (Bagby 2012). As such, mosques depend mainly on unpaid volunteers to manage their events and activities. Similar to imams, volunteers are likely to experience burnout as many mosque boards display an aversion towards compensating staff members. Detailing the issue, Imam Michael stated, "we need to put our money where our mouth is if we say we want to run professional organizations. We have to take actual steps towards doing that, and a volunteer board cannot run a large organization or the day-to-day activities of the place." Adding to the problem is how mosque boards then choose to funnel resources towards building a larger Islamic center (preference of the board) instead of investing in human capital (preference of the imams). Two respondents, Imams Erick and Steven, definitively maintained the stance that finances should be distributed differently, and this difference in vision was another reason for their resignations.

In the experiences of this study's sample, imams struggled to maintain a healthy and mutualistic working relationship with their respective committee boards. For the imams that especially resigned from their positions, they viewed their board mem- 
bers as individuals who sought control over the institution in general, and the imam in particular. According to the transcripts, three underlying and prominent factors explained issues between the board and the imams in this sample. Organizational challenges, cultural differences, and clashes in vision were critical reasons that impaired the work environment, according to my respondents.

\section{Whether It Is Advantageous Being an American- Born Imam}

As aforementioned, one of the primary motivational factors for exploring this study was the palpable excitement expressed by congregants of a community upon knowing that an American-born imam was being hired. Relatedly, a question that was discussed in my interviews was whether my respondents' experiences boded well for future American-born imams or if foreign-born imams could aptly fill open imam positions. In specific, my sample was asked to compare and contrast the hiring of an American-born imam as opposed to a foreign-born imam. There was a slight difference of opinion with my sample, where most respondents (seven imams) opined that American-born imams needed to fill open imam positions over foreign-born imams. Conversely, two imams felt that there were no differences between who was hired as long as the imam was culturally competent, and the ability to display this quality may lead the two participants to favor a foreign-born imam.

\section{No True Advantage to Being American-Born}

Beginning with the minority of respondents, it was Imams William and Tristan who did not conclude that an imam's birthplace was a predictor of an effective and successful imam. As a proponent of this viewpoint, Imam Tristan was keen on mentioning his lack of proclivity towards a foreign-born or American-born imam. About who was more suitable for employment, Imam Tristan commented, "different Islamic centers have things in common, but also differences, so it doesn't work the same everywhere. So, you won't necessarily have a good fit in some communities. But, it's hard to generalize about that." Likewise, emphasizing the point of considering each community as particular cases, Imam William said, "media, pastoral care, youth work. In some mosques, the imams have facilities and logistics, and administrative roles. And so each one has to define what the congregations' needs are; obviously, people can come in with a breadth of experience, and they have competence in some areas." In addition, Imams William and Tristan stated that a central attribute that mitigates against the need for hiring an American-born imam lies in the ability of an imam to become acclimated with the American community in general, and their local community in specific. Adapting to their local contexts was not quixotic, according to Imams William and Tristan, and communities should not adopt sweeping generalizations that affect their decision-making upon hiring a new imam.

What was apparent from the transcripts with Imams William and Tristan was their non-preference of an American-born imam over a foreign-born imam. However, an intriguing and subtle conclusion of Imam William was that he felt that a foreign-born imam was more of an appropriate hire for smaller Muslim communities. One may make a distinction that Imam William differentiated who would be a better hire based on the size of the community, but in his silence on larger communities, there was no general rule that pointed to favoring an American-born imam, in his opinion. 


\section{American-Born Imam Is Preferred}

The majority of my respondents expressed their preference for hiring an American-born imam over a foreign-born imam. Several factors were cited by these respondents that guided their rationale, namely, the political climate post 9/11, socio-cultural differences (see: Nyang 1999), and linguistic advantages favoring American-born imams. Of the most significant was 9/11, as the involvement of Muslim communities in social and political activism was under the spotlight (Bagby 2009; Al-Krenawi 2016). After 9/11, restrictions on visas granted for imams to work in the United States led to a growing need for American imams to fill the void.

In my study, in terms of cultural understanding, an emphasis was made by the proponents of American-born imams over foreign-born imams due to their extensive experience with the American context. In this study's sample, most of my respondents strongly advocated for American-born imams and desired a change demographically of who served as an imam nationwide. Imam Jacob stated the percentage should shift from the current $85-90 \%$ where immigrants serve as imams to where $85-90 \%$ of imams are born and raised in America. These attitudes were likewise found among Muslim congregants, where studies have shown that communities become dissatisfied with an imam who cannot address religious and secular issues of first- and second-generation Muslims (Ul Mobeen 2012; Al-Krenawi 2016).

From a symbolic interactionist lens, shared meanings of American culture have assisted Imam Jacob when speaking to the concerns of Muslim youth and displaying the ability to relate to non-Muslims socio-culturally. Amplifying this attitude was Imam Michael, who said, “A foreign-born imam doesn't know what it means to work a 9 to 5 job. Doesn't know what it means to have a household where, say, for example, the father is working, and the mother is working, and the kids have their schedule because they didn't grow up with that and didn't see that." In addition, Imam Michael objected pedagogically with foreign-born imams as they lacked the cultural competency when he said,

And so I saw people in the masjid who don't understand the American Muslim experience, and they are lecturing me about how to live, and I couldn't sit knowing that ability you had in giving more. So, until there was actually a formal opening in one of the masjid [mosques] for a position, that's when I first started considering the position. And I felt that I had more to offer because I was born and raised here, and I know the American mindset; why not go into this field?

Some respondents, notably Imam Stanley, recalled that the Muslim community's socio-demographic makeup is the majority being American-born, which should coincide with more American-born imams being hired.

Moreover, another factor cited as an advantage for hiring an American-born imam over a foreign-born imam was the awareness of potential professional development opportunities. Specifically, these opportunities consist of access to training opportunities and social activist causes based on the relationships formed with interfaith groups. The respondents in my sample believed that overseas imams struggle to build alliances with marginalized communities, especially Black communities and communities of color. Both Imams Stanley and Malcolm expressed the necessity for imams to form coalitions based on social justice, and this advantage was afforded more strongly in favor of an American-born imam as Imam Malcolm articulated, 
I think one of the biggest advantages is knowing the topography of this land, and we know...and actually being an African American. Because we've struggled and came out of slavery, there's people here, and we're better equipped to deal with them, and so it was a mistake for any of the immigrants not to align themselves with us. Many of them recognize now that they should've done that and not set themselves up somewhere else, because we know how to deal with that.

Lastly, the justification for employing an American-born imam over a foreign-born imam was based on proficiency in the English language. The ability to communicate, written and oral, using the English language was a significant asset that worked in the favor of American-born imams. Imam Michael vented,

The language is so important, and I'll be very honest, I'm still frustrated on a national stage, it sort of seems you see thickly accented people where their command of English is fine maybe, but it's a disconnect that you're building with society. Look, this is who Muslims are, no, that's not who Muslims are, and why is this person representing who I am and what I am about. We are trying to represent the Muslim American faith, so those kinds of things are very frustrating and also translate into how we address communities.

In my sample, imams mentioned that through social media and other online platforms, audio and video recordings of their sermons could have a global impact as English continues to gain a universal audience. The importance of language has been found in Morgan (2013), where-due to their foreign accents-immigrant clergy across various faiths struggle to communicate their messages clearly.

The inductively concluded theme of preferring an American-born imam over a foreign-born imam re- quires further empirical analysis. Although the theme was apparent in the interviews conducted, and most respondents shared their preferences for an American-born imam, more data collection is required that would enable a comparative investigation. Nevertheless, in this sample, seven respondents were more inclined towards hiring more American-born imams. Two respondents did not acknowledge a true difference in hiring an imam based on national origin-as long as cultural competency was displayed.

\section{Discussion and Conclusion}

My study's goal was to understand the personal perspectives, challenges, and career paths of American-born imams. Several implications emerge from the findings of this study. Amongst the implications that may benefit in understanding the challenges and career paths of imams is the intersectional analysis of gender and race. Since a finding of this study was the lack of exclusionary standards for the imam position related to gender and race, studies are needed that shed light on the path of women and minorities as Muslim leaders. Symbolic interactionism provides a suitable theory for understanding the individual "self" and identity (Blumer 1969), particularly of women and non-Arab imams. Questions arise about how the challenges and professional progressions differ by race and gender, where social issues such as prejudice and discrimination may be at the forefront. Another implication based on the findings of this study is the continued need for training. Professional training seems to be a dire need and includes non-profit institutional management for board members and professional development workshops for imams themselves. In such training, emphasis should be on workshops that lend to professional development and leadership, increased public engagement with local officials 
and student organizations, interfaith coalitions, media relations, and social justice issues.

Additional research is required explicating the differences between American-born imams and foreign-born imams. A topic of profound consequence, this study's sample believed that the future of Muslim leadership was largely contingent on the messenger, which would then shape the message itself to the Muslim community in particular, and the American society in general. As such, imams in my sample have been tasked with immense and vast communal responsibilities that are not required of overseas imams. Hence, a need arises for the development of Muslim seminaries and institutions that focus on leadership training domestically.

Here, I suggest a potential program that would assist in the development of aspiring imams. Specifically, I recommend that mosques and leadership seminaries construct an imam internship program that would be paid for by the hosting institution. In this program, after undergoing an interview, the intern would shadow an American-born imam for some time in a community that is foreign to the intern. Contributing to the development of the intern, they would be involved in the following activities:

1. Participate in meetings with board and committee members.

2. Prepare for and give Friday sermons.

3. Conduct town hall meetings with community members to discuss the needs and issues of the community.

4. Participate in local interfaith and social justice initiatives.
5. Coordinate meetings with college and university clubs such as the Muslim Student Association.

6. Address the local media regarding matters related to the Muslim community.

Transitioning to mosque boards, here I provide some recommendations to board members that would facilitate a positive and collaborative work environment. As it relates to my theme of challenges with board relations, imams work under a board that is mostly older than the imam. As chronicled in the documentary UnMosqued (2014), the average age of a board member in American mosques was 52. This represents generational issues that impact an imam's vision regarding the organizational structure of an institution. As such, board members should consider grooming the Muslim youth through mentorship programs. In addition, board members should come into their positions without the expectation that they should serve multiple terms or accept lifetime membership. As a result, an institution will continue to have diverse voices and opinions that are valued within the Muslim organization. Furthermore, of significant importance is that board and committee members address staffing issues within Muslim organizations and rely less on unpaid volunteers. Muslim organizations should budget for paid employees and staff besides simply compensating the imam.

The significance of my study was that it provided a platform for imams to voice their concerns and perspectives, which offered insight into the trajectory of Muslim leadership in America. Utilizing only qualitative data, this study was limited as an exploratory study as it relied on a small sample size. However, the limitations of this study provide an avenue for future research that delves into differences 
between mosque leadership models and a comparative study between American-born imams and foreign-born imams. To conclude, further research could investigate the attitudes and the perspectives of Muslim congregants regarding the imam they would prefer to serve as their community leader.

\section{References}

Abbasi, Farha and Reham F. Gassas. 2016. "Stress and Resilience for Imams and Chaplains." Dearborn, MI. Presentation.

Abdul-Hakeem, Nazeeh Z. 2015. The Athaan in the Bull City, Building Durham's Islamic Community. Morrisville, NC: Lulu Publishing Services.

Abu-Bader, Soleman H., M. Taqi Tirmazi, and Fariyal Ross-Sheriff. 2011. “The Impact of Acculturation on Depression among Older Muslim Immigrants in the United States." Journal of Gerontological Social Work 54(4):425-448.

Abuelezz, Muhammad. 2011. A Survey of American Imams: Duties, Qualifications, and Challenges. A Quantitative and Religious Analysis. Master's thesis, Department of Religion, University of Georgia, Athens, GA.

Al-Ghazali, Muhammad. 1999. Figh Us-Seerah. Understanding the Life of Prophet Muhammad. Riyadh, Saudi Arabia: IIPH.

Al-Islam, Amir. 2006. “Educating American Muslim Leadership (Men and Women) for the Twenty-First Century." Teaching Theology and Religion 9(2):73-78.

Al-Krenawi, Alean. 2016. "The Role of the Mosque and Its Relevance to Social Work." International Social Work 59(3):359-367.

Ali, Osman M., Glen Milstein, and Peter M. Marzuk. 2005. “The Imam's Role in Meeting the Counseling Needs of Muslim Communities in the United States." Psychiatric Services 56(2):202-205.

Ansary, Tamim. 2009. Destiny Disrupted. New York: Public Affairs.

Aronson, Elliot, Timothy D. Wilson, and Robin M. Akert. 2007. Social Psychology. Upper Saddle River, NJ: Pearson Prentice Hall.
Askar, Anas. 2017. American Born Imams: Negotiating Clerical Responsibilities and Expectations. Master's thesis, Department of Sociology, East Carolina University, Greenville, SC.

Babbie, Earl. 2004. The Practice of Social Research. Belmont, CA: Thomson Wadsworth.

Bagby, Ihsan. 2009. “The American Mosque in Transition: Assimilation, Acculturation and Isolation." Journal of Ethnic and Migration Studies 35(3):473-490.

Bagby, Ihsan. 2012. “The American Mosque 2011 Report Number 1 and 2 from the US Mosque Study 2011." Islamic Society of North America 1, 2:1-58.

Blumer, Herbert. 1969. Symbolic Interactionism: Perspective and Method. Englewood Cliffs, NJ: Prentice-Hall.

Burnett, John. 2013. “As Islam Grows, U.S. Imams in Short Supply." NPR, February 10. Retrieved June 14, 2021 (http://www. npr.org/2013/02/10/171629187/as-islam-grows-u-s-imams-inshort-supply).

Charon, Joel M. 1979. Symbolic Interactionism: An Introduction an Interpretation an Integration. Englewood Cliffs, NJ: Prentice-Hall.

Cooley, Charles Horton. 1927. Social Organization. A Study of the Larger Mind. New York: Charles Scribner's Sons.

Denzin, Norman K. and Yvonna S. Lincoln. 2013. The Landscape of Qualitative Research. Thousand Oaks, CA: Sage Publications.

Djedi, Youcef. 2011. "Max Weber, Islam and Modernity." Max Weber Studies 11(1):35-67. 
Gattino, Silvio et al. 2016. "Muslim Acculturation in a Catholic Country: Its Associations with Religious Identity, Beliefs, and Practices." Journal of Cross-Cultural Psychology 47(9):1194-1200.

Haddad, Yvonne Y. 1999. “The Globalization of Islam.” Pp. 601641 in The Oxford History of Islam, edited by J. L. Esposito. New York: Oxford University Press.

Haddad, Yvonne Y. and Adair T. Lummis. 1987. Islamic Values in the United States. New York: Oxford University Press.

Hammersley, Martyn. 2010. "The Case of the Disappearing Dilemma: Herbert Blumer on Sociological Method." History of the Human Sciences 23(5):70-90.

Howard, Judith A. 2000. "Social Psychology of Identities." Annual Review of Sociology 26(1):367-393.

Ibn Khaldun, Abdur Rahman M. 1967. Al-Muqaddimah. Princeton, NJ: Princeton University Press.

Lipka, Michael. 2017. "Muslims and Islam: Key Findings in the U.S. and around the World." Pew Research Center, February 27. Retrieved June 14, 2021 (http://www.pewresearch.org/facttank/2017/02/27/muslims-and-islam-key-findings-in-the-u-s-andaround-the-world/).

Manley, Marc. 2015. “Statement of Resignation from Islamic Center of Inland Empire as Religious Director." Marc Manley, June 29. Retrieved June 14, 2021 (http://www.marcmanley.com/statement-of-resignation-from-islamic-center-of-inland-empire-as-religious-director/).

Morgan, John H. 2010. "Professionalization of Islamic Ministry in America: Components of the Legitimizing Process in Western Society." Journal for the Study of Religions and Ideologies 9(26):114-127.

Morgan, John H. 2013. "Disentangling Religion and Culture: Americanizing Islam as the Price of Assimilation." International Journal of Islamic Thought 4:28-36.

Nyang, Sulayman S. 1999. Islam in the United States of America. Chicago: ABC International Group.
Omar, Abdul Mannan. 2005. Dictionary of the Holy Quran. Hockessin, DE: Noor Foundation International.

Pooler, David K. 2011. “Pastors and Congregations at Risk: Insights from Role Identity Theory." Pastoral Psychology 60(5):705-712.

Rashaad, Khalis. 2015. "A Case for the Bivocational Imam." Ummah Wide, July 07. Retrieved June 14, 2021 (https:/ummahwide. com/a-case-for-the-3141bd455889\#.bezl7d0cq).

Rock, Paul. 1979. The Making of Symbolic Interactionism. Totowa, NJ: Rowman and Littlefield.

Scheuringer, Brunhilde. 2016. "Multiple Identities: A Theoretical and Empirical Approach." European Review 24(3):397-404.

Stark, Rodney and Lynne Roberts. 1996. Contemporary Social Research Methods. Bellevue, WA: MicroCase Corporation.

U1 Mobeen, Noor. 2012. Muslim Leadership in America. Ph.D. dissertation, Department of Agricultural Leadership, Education \& Communication, Texas A\&M University, College Station, TX.

Van Sertima, Ivan. 2003. They Came Before Columbus. The African Presence in Ancient America. New York: Random House Trade Paperbacks.

Vitello, Paul. 2010a. "Taking a Break from the Lord's Work." The New York Times, August 01. Retrieved June 14, 2021 (http://www. nytimes.com/2010/08/02/nyregion/02burnout.html?_r=0).

Vitello, Paul. 2010b. "Islamic Center Exposes Mixed Feelings Locally." The New York Times, August 19. Retrieved June 14, 2021 (http://www.nytimes.com/2010/08/20/nyregion/20muslims.html?pagewanted=all).

Weber, Max. 1993. The Sociology of Religion. Boston, MA: Beacon Press.

Wehr, Hans. 1994. A Dictionary of Modern Written Arabic: Arabic-English. Urbana, IL: Spoken Language Services.

Zaman, Saminaz. 2008. "From Imam to Cyber-Mufti: Consuming Identity in Muslim America." The Muslim World 98(4):465-474.

\section{Citation}

Askar, Anas. 2021. "An Exploratory Study on American-Born Imams: Negotiating Pastoral Responsibilities and Expectations." Qualitative Sociology Review 17(3):90-106. Retrieved Month, Year (http://www.qualitativesociologyreview.org/ENG/archive_eng. php). DOI: https://doi.org/10.18778/1733-8077.17.3.05 